tâm $Y$ tế huyện Sông Hinh, tỉnh Phú Yên vào năm 2020 trong giai đoạn biến động về cơ cấu tổ chức của trung tâm $Y$ tế huyện. Kết quả chỉ ra tỷ lệ gắn kết của NVYT với Trung tâm Y tế huyện Sông Hinh ở mức trung bình. Trong các cấu phần của sự gắn kết, cấu phần niềm tự hào là cấu phần cần được khắc phục nhất.

\section{TÀI LIÊU THAM KHẢO}

1. O'Reilly C. and Chatman J. (1986), 'Organizational commitment and psychological attachment: The effects of compliance identification, internalization of prosocial behaviors', Journal of Applied Psychology, 71, p. 492-499.

2. Allen, $N$. and J. Meyer. (1990). The measurement and antecedents of affective, continuance, and normative commitment to the organization. Journal of Occupational Psychology, No. $63,1-18$.
3. Đỗ Phú Trân Tình và Cộng sự (2012), 'Phân tích các nhân tố ảnh hưởng đến sư gắn bó lâu dài của nhân viên trẻ với doanh nghiệp $p^{\prime}$, Tạp chí phát triển và hội nhập, 7, tr. 54 - 60 .

4. S.M and Akhtar. N Azeem (2014), "Job satisfaction and organizational commitment among public sector employees in Saudi Arabia. nternational Journal of Business and Social Science, 5(7), p. $128-133$.

5. Trân Thị Bích Ân (2017), 'Sư gắn bó của điều dưỡng lấm sàng với bệnh viển quận Thủ Đức Thành phố Hồ Chí Minh̀ và một số yếu tố liên quan', Luận văn Thạc sĩ Y tế Công cộng, Hà Nội.

6. Mowday, Richard $T$, Richard $M$ Steers and Lyman W Porter, (1979). The measurement of organizational commitment. Journal of Vocational Behavior, No.14, pp. 224-247.

7. Trân Kím Dung (2011). Quản trị nguồn nhân lực. Nhà xuất bản Thống kê, Hà Nôi

8. Nehrir B., Ebadi Abas, Toufighi Shahram, et al. Relationship of job satisfaction and organizational commitment in hospital nurses. Journal of Military Medicine. 2010.

\title{
ĐĂC ĐIỂM CÁC VÙNG PHỔI THEO THANG ĐIỂM SIÊU ÂM PHỔI Ở BÊNH NHÂN SUY HÔ HẤP CẤP TIẾN TRIỂN ĐƯợC THÔNG KHÍ XÂM NHẬP
}

\section{TÓM TẮT}

Mục tiêu: Mô tả đăc điểm các vùng phổitheo bảng điểm siêu âm phổi ở bệnh nhân suy hô hấp cấp tiến triển (Acute Respiratory Distress Syndrome ARDS) được thông khí xâm nhâp. Đối tượng và phương pháp nghiên cứu: Nghiên cứu mồ tả tiến cứu thực hiên trên 24 bênh nhân ARDS được thông khí xâm nhập tại khoa Cấp cứu và khoa Hồi sức tích cực bệnh viện Bạch Mai từ tháng 10/2019 đến tháng 10/2020. Siểu âm được thực hiệntrên 12 vùng phổi theo bảng điểm siêu ẩm phổi điểm cao nhất 3 điểm khi có hình ảnh đông đặc, thấp nhất là 0 điểm khi có hình ảnh $\mathrm{A}$ - line. Phân tích phân bố của hình ảnh siêu âm phổi này theo mức độ nặng của ARDS và theo các vùng của phổi bằng phân mềm thống kê y học SPSS 20.0. Kết quả nghiên cứu: Nghiên cứu thực hiện 64 lần siêu âm phổi trên 24 bệnh nhân ARDS được thông

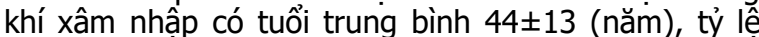
nam: nữ là $2: 1$. Hình ảnh đông đặc và $B$ - line xuất hiên chủ yếu tại vùng sau, dưới của phổi. Hình ảnh B2 xuất hiện ở $100 \%$ bệnh nhân nghiên cứu. Bệnh nhân ARDS nặng có nhiêu hình ảnh B2 (75\%), C (75\%) tuy

\footnotetext{
${ }^{1}$ Trung tâm Cấp cứu A9- Bênh viên Bach Mai,

${ }^{2}$ Trung tâm Chống độc - Bệnh viện Bạch Mai

${ }^{3}$ Trường Đại học Y Hà Nọii,

Chịu trách nhiệm chính: Đỗ Ngọc Sơn

Email: sonngocdo@gmail.com

Ngày nhận bài: 4.3.2021

Ngày phản biên khoa họ: 27.4.2021

Ngày duyệt bài: 7.5.2021
}

Đỗ Ngọc Sơnn ${ }^{1}$, Đặng Thị Xuân², Đặng Duy Hiển ${ }^{3}$

nhiên điểm siêu âm phổi tổng và từng vùng không tăng dân theo mức độ nặng theo phân loại Berlin 2012. Kết luâan: Hình ảnh siêu âm phân bố không đều giữa các vùng phổi với hình ảnh đông đặc, B2 tập trung chủ yếu tai vùng sau, dưới của phối.

Tư khóa: suy hố hấp cấp tiến triển, bảng điểm siêu âm phổi.

\section{SUMMARY \\ CHARACTERISTICS OF LUNG REGIONAL DISTRIBUTION BY LUNG ULTRASOUND SCORE IN PATIENTS WITH ACUTE RESPIRATORY DISTRESS SYNDROME ON INVASIVE VENTIATION}

Objective: to describe lung regional distribution by lung ultrasound score in patients with Acute Respiratory Distress Syndrome (ARDS) on invasive ventilation. Patients and Methods: A prospective observational study was carried outon 24 patients with ARDS who were on invasive ventilation at the Emergency Department and Intensive Care Unit of Bach Mai Hospital from October 2019 to October 2020. Lung ultrasound was performed on the 12 regions according to the lung ultrasound score, the highest score was 3 points with consolidation, the lowest was 0 points with the A - line. Analysis of the distribution of the lung ultrasound images by the severity of ARDS and by lung regional areas, using medical statistical software SPSS 20.0. Results: 64 lung ultrasounds were performed on 24 ARDS patients on invasive ventilation with an average age of $44 \pm 13$ 
(years), the men:women ratio was 2:1. Consolidation and $\mathrm{B}$-line image appeared mainly in the posterior and lower areas of the lung, B2 image appeared in 100\% of patients. Majority of patients with severe ARDS showed B2 image on their lungs (75\%), C (75\%), but the total and regional ultrasound scores did not change accordingly to the severity of ARDS (Berlin 2012) .Conclusion:Lung ultrasonography showed heterogeneously in distribution between lung areas with consolidation and B-line image appeared mainly in the posterior and lower areas of the lung.

Keyword: Acute respiratory distress syndrome, lung ultrasound score.

\section{I. ĐĂT VẤN ĐỀ}

Hội chứng suy hô hấp cấp tiến triển (ARDS) rất thường gặp trong các khoa hồi sức cấp cứu có tỷ lệ tử vong cao và di chứng nặng nề. Đặc trưng của ARDS là tổn thương màng phế nang mao mạch lan tỏa, tăng tính thấm mao mạch phổi, làm cho dịch và các chất có trong lượng phân tử cao từ trong lòng mạch thoát ra ngoài khoảng kẽ vào phế nang dẫn đến mất thể tích thông khí bình thường còn gọi là hiện tượng "phối nhỏ"(baby lung). Bên cạnh đó tổn thương phổi trong ARDS phân bố không đồng đều mà phụ thuộc theo chiêu trong lực nên hình ảnh đông đặc tập trung chủ yểu tại vùng đáy sau hai bên ${ }^{1}$. Hiện nay, chụp $X$ quang và chụp cắt lớp vi tính lồng ngực vẫn là phương pháp chẩn đoán hình ảnh thường dùng để đánh giá tổn thương phổi ở bệnh nhân ARDS. Tuy nhiên, hai phương pháp này tồn tại những nhược điểm nhất định như không chính xác, không phổ biến, giá thành cao, tăng phơi nhiễm với tia $X$, rủi ro khi vận chuyển bệnh nhân. Gần đây nhiều nghiên cứu về giá trị của siêu âm phổi trong ARDS và thu được những kết quả nhất định. Tương tự như $C T$, siểu âm phổi có khả năng đánh giá tốt thông khí từng vùng phổi, nên được ứng dụng trong theo dỗi đáp ứng khi thực hiện nghiệm pháp huy động phế nang, thông khí nằm sấp, $\mathrm{ECMO}^{2}$. Ngoài ra, dựa vào hình ảnh siêu âm thu được có thể phân loại được dạng tổn thương khu trú hay lan tỏa, có giá trị trong việc lựa chọn chiến lược thông khí cũng như tiên lượng tử vong. Bảng điểm siêu âm phối (Lung Ultrasound Score - LUS) lần đầu được giới thiệu bởi Bouhemad, thực hiện trên 12 vùng phổi, tính toán dựa trên các dấu hiệu $\mathrm{A}$ line, B line, đông đặc phổi, đã được chứng minh là công cụ tốt để đánh giá thông khí các vùng của phổi ${ }^{3}$. Hơn nữa siêu âm phổi có ưu điểm tiện dụng, thực hiện tại giường, chi phí thấp và dễ dà̀ng lập lại. Hiện tại ở Việt Nam siêu âm phổi vẫn còn là vấn đề mới, chưa có nhiều nghiên cứu áp dụng siêu âm phổi trên bệnh nhân ARDS, vì vậy chúng tôi tiến hành đề tài này nhằm mục tiêu mô tả đặc điểm các vùng phổi theo bảng điểm siêu âm phổi ở bệnh nhân suy hô hấp cấp tiến triển (Acute Respiratory Distress Syndrome - ARDS) được thông khí xâm nhập.

\section{II. ĐỐI TƯợNG VÀ PHƯƠNG PHÁP NGHIÊN CỨU}

1. Đối tượng nghiên cứu. Bệnh nhân ARDS được thồng khí xâm nhập điều trị tại khoa Cấp Cứu và khoa Hồi sức tích cực bệnh viện Bạch Mai thời gian từ 10/2019 - 10/2020.

\subsection{Tiêu chuẩn lựa chọn}

- Bệnh nhân chẩn đoán ARDS theo tiêu chuẩn Berlin $2012^{4}$

- Thông khí nhân tạo xâm nhập $\geq 48 h$

- Tuổi $\geq 16$

\subsection{Tiêu chuẩn loại trừ}

- Rối loạn huyết động nặng không thể thay đổi tư thế

- Dị dạng lông ngực nặng, tràn khí dưới da không thể thăm dò bằng siêu âm

- Bệnh nhân và người nhà từ chối tham gia vào nghiên cứu

\section{Phương pháp nghiên cứu}

Thiết kế nghiên cứu: nghiên cứu mô tả tiến cứu

\section{Phương tiện nghiên cứu}

- Máy siêu âm SonoSite Edge 2 hãng Fujifilm có đâu dò cong tần số 3 - $8 \mathrm{MHz}$ và máy siêu âm LOGIQ P7 của hãng G.E có đâu dò cong tân số 1 $-5 \mathrm{MHz}$.

- Máy phân tích khí máu Stat Profile Phox Ultra của hãng NOVA biomedical

- Máy thở The Puritan Bennett 840 của hãng Medtronic sản xuất tại Ireland

- Máy monitor GE theo dõi tân số tim, tân số thở, SpO2, huyết áp không xâm nhập và huyết áp động mạch xâm nhập, áp lực tĩnh mạch trung tâm. Các máy xét nghiệm khác: tại labo trung tâm bệnh viện Bạch Mai

\section{Quy trình nghiên cứu}

- Lựa chọn tất cả những bệnh nhân đủ tiêu chuẩn trong thời gian nghiên cứu

- Điều trị chuẩn theo quy trình điêu trị của Khoa cấp cứu và Hồi sức tích cực

- Siêu âm tại 12 vùng phổi, ghi lại hình ảnh thu được mỗi vùng theo bảng điểm siêu âm phổi tại thời điểm to (vào viện), t0 +24h, to + 48h

-Xử lý và phân tích số liệu theo mục tiêu

\section{Quy trình siêu âm phổi.}

\section{Chuẩn Bị:}

* Người thực hiện: Bác sỹ được đào tạo về siêu âm phổi, một người hỗ trợ, một chuyến gia chẩn đoán hình ảnh. 
* Dụng cụ: Máy siêu âm Sonosite của hãng Fujifilm có đầu dò cong tần số $3-8 \mathrm{MHz}$, máy siêu âm LOGIQ P7 của hãng G.E có đầu dò cong tần số $1-5 \mathrm{MHz}$, máy monitor GE theo dõi, bô nhớ USB ghi lại video, hình ảnh siêu âm phổi

* Bệnh nhân: tư thế nằm ngửa, đầu bằng.

\section{Tiến hành.}

Bước 1: Kiểm tra dấu hiệu sinh tồn: Mạch, huyết áp, $\mathrm{SpO}$, phải đảm bảo tình trạng huyết động ổn định trước khi tiến hành siêu âm. Kiểm tra tình trạng ống nội khí quản, đường truyền catheter.

Bước 2: Mỗi bên phổi được chia thành 3 vùng trước, bên, sau bằng các đường giữa xương ức, đường nách trước, đường nách sau. Mỗi vùng này lại được chia làm phần trên và phần dưới bởi đường nằm ngang đi qua khoang liên sườn 5 được đánh dấu bởi bút mực.

Bước 3: Siêu âm lần lượt 8 vùng ở phía trước và bên của hai bên phổi.

Tiếp theo, người hỗ trợ nghiêng bệnh nhân, bộc lộ lần lượt vùng phía sau hai bên phổi. Bác sỹ tiến hành siêu âm 4 vùng phổi còn lại phía sau hai bên.

Siêu âm sử dụng lát cắt ngang: đầu dò cắt ngang qua 2 cung sườn và vuông góc với xương sườn. Định hướng đầu dò quay lên phía đầu, chì điểm màn hình ở góc bên trái. Hình ảnh của siêu âm phổi được lưu lại trên USB có đánh dấu chú thích vùng phổi và thời điểm được siêu âm (t0, t0 + 24h, t0 + 48h).

\section{Đánh dấu các vùng phổi quy ước:}

L1: vùng trước trên trái , $L 2$, vùng trước dưới trái, L3: vùng bên trên trái, $L 4$ : vùng bên dưới trái, L5: vùng sau trên trái, L6 vùng sau dưới trái, R1: vùng trước trên phải, $R 2$, vùng trước dưới phải, R3: vùng bên trên phải, R4: vùng bên dưới phải, R5: vùng sau trên phải, R6 vùng sau dưới phải

Bác sỹ thực hiên ghi điểm từng vùng vào mẫu nghiên cứu dựa trên nhận định hình ảnh siêu âm như sau: 0 điểm - đường $A$ hoặc đường $B$ nhưng số lượng $\leq 3,1$ điểm: đường $B 1$ : số lượng đường $B$ lớn hơn 3 , khoảng cách ngang giữa các đường $B>3 \mathrm{~mm}$, 2 điểm: đường $B 2$ : số lượng đường $B$ lớn hơn 3 khoảng cách ngang giữa các đường $B<3 \mathrm{~mm}, 3$ điểm: hình ảnh đông đặc phổi.

Hình ảnh, video siêu âm phổi của 12 vùng được đánh giá lại bởi chuyên gia chẩn đoán hình ảnh được làm mù, không biết về các dữ liệu lâm sàng của bệnh nhân.

Điểm LUS cuối cùng ghi nhận theo chuyên gia chẩn đoán hình ảnh.
Lưư ý: khi bệnh nhân được thông khí nhân tạo nằm sấp, bệnh nhân được siêu âm theo thứ tự vùng sau, vùng bên, vùng trước.

Bước 4. Đưa bệnh nhân về tư thế ban đầu. Kiểm tra dấu hiệu sinh tồn: $M, \mathrm{HA}, \mathrm{SpO} 2$, kiểm tra tình trạng catheter, ống nội khí quản

3. Phương pháp xử lý số liệu: Các số liệu được phân tích theo phương pháp thống kê y học, trên chương trình SPSS 20.0. Các thuật toán sử dụng bao gồm: Mô tả trung bình và độ lệch chuẩn cho biến định lượng phân bố chuẩn và mô tả trung vị và tứ phân vị cho biến không chuẩn. Mô tả tần số và tỉ lệ phần trăm cho biến định tính. Các biến liên tục có phân phối chuẩn được kiểm tra bằng phép thử Kolmogorov-Smirno, so sánh bằng phép thử T-Test.Sự khác biệt có ý nghĩa thống kê khi $p<0,05$.

\section{KẾT QUẢ NGHIÊN CỨU} cứu

\section{1. Đặc điểm chung của đối tượng nghiên}

Bảng 1.1. Đặc điểm nhân khẩu học của đôî tượng nghiên cứu

\begin{tabular}{|c|c|c|}
\hline $\begin{array}{c}\text { Đặc điếm nhân khấu } \\
\text { học }\end{array}$ & $\begin{array}{c}\text { Tân số } \\
\text { (n) }\end{array}$ & $\begin{array}{c}\text { Ti lêê } \\
\text { (\%) }\end{array}$ \\
\hline Giới tính & & \\
\hline Nam & 16 & 67 \\
\hline Nữ & 8 & 33 \\
\hline $\begin{array}{c}\text { Tuổi nghiên cứu (năm) } \\
\text { (Trung bình } \pm \text { SD) }\end{array}$ & $\begin{array}{c}44 \pm 13 \text { (năm) } \\
\text { Cao nhất: } \\
\text { nhất: } 16\end{array}$ \\
\hline Tống & $\mathbf{2 4}$ & $\mathbf{1 0 0}$ \\
\hline
\end{tabular}

Nhận xét: Đối tượng nghiên cứu là nam giới chiếm tỷ lệ cao với độ tuổi trung bình tương đối thấp.

Bảng 1.2. Nguyên nhân ARDS

\begin{tabular}{|c|c|c|}
\hline Nguyên nhân & $\begin{array}{c}\text { Tân số } \\
\text { (n) }\end{array}$ & $\begin{array}{c}\text { Tỷ lệ } \\
(\mathbf{\%})\end{array}$ \\
\hline Taii phổi & 19 & 79,1 \\
\cline { 2 - 3 } Viêm phổi do vi khuẩn & 7 & 29,2 \\
\cline { 2 - 3 } Viêm phổi do virut & 1 & 4,2 \\
\cline { 2 - 3 } Viêm phổi do nấm & 3 & 12,5 \\
\cline { 2 - 3 } Viêm phổi chưa rõ căn nguyên & 8 & 33,3 \\
\hline Duối nước & 3 & 12,5 \\
\hline Nhiêm khuấn ngoài phối & 2 & 8,3 \\
\hline
\end{tabular}

Nhận xét: Nguyên nhân ARDS phần lớn là tại phối, trong nhóm này có $1 / 3$ bệnh nhân chưa xác được căn nguyên vi sinh gây bệnh

Bảng 1.3. Tý lệ các biện pháp điều trị

\begin{tabular}{|c|c|c|}
\hline Biện pháp điều trị & Tần số & Tỷ lệ (\%) \\
\hline An thần & 24 & 100 \\
\hline Giãn cơ & 20 & 83 \\
\hline Kháng sinh & 24 & 100 \\
\hline Kháng nấm & 3 & 12,5 \\
\hline Kháng virus & 2 & 8,3 \\
\hline
\end{tabular}




\begin{tabular}{|c|c|c|}
\hline Lọc máu liên tục & 16 & 66,7 \\
\hline Nằm sấp & 9 & 37,5 \\
\hline Mở phổi & 3 & 12,5 \\
\hline Tuân hoàn ngoài cơ thể & 1 & 4,2 \\
\hline
\end{tabular}

Nhận xét: $100 \%$ bệnh nhân được sử dụng thuốc an thần, kháng sinh. Tỷ lệ bệnh nhân được lọc máu liên tục $2 / 3$ số bệnh nhân; nằm sấp được triển khai trên nhiều bệnh nhân.

Bảng 1.3. Chỉ số lâm sàng ngày thứ nhất Chỉ số Trung bình \pm độ lệch chuẩn

\begin{tabular}{|c|c|}
\hline SOFA & $9 \pm 5$ \\
\hline LIS & $2,8 \pm 0,5$ \\
\hline $\begin{array}{c}\text { Độ giãn nở phối } \\
\text { (mL/cm H2O) }\end{array}$ & $25,8 \pm 7,5$ \\
\hline PaO2/FiO2(mmHg) & $171 \pm 67$ \\
\hline LUS & $21,9 \pm 4,2$ \\
\hline
\end{tabular}

Nhận xét: Chỉ số SOFA, LIS, LUS của nhóm nghiên cứu trong ngày thứ nhất tương đối cao, trong khi đó có sự giảm mạnh về độ giãn nở phổi và chỉ số $\mathrm{PaO} 2 / \mathrm{FiO} 2$

\section{2. Đặc điểm hình ảnh siêu âm phổi theo bảng điểm siêu âm phổi}

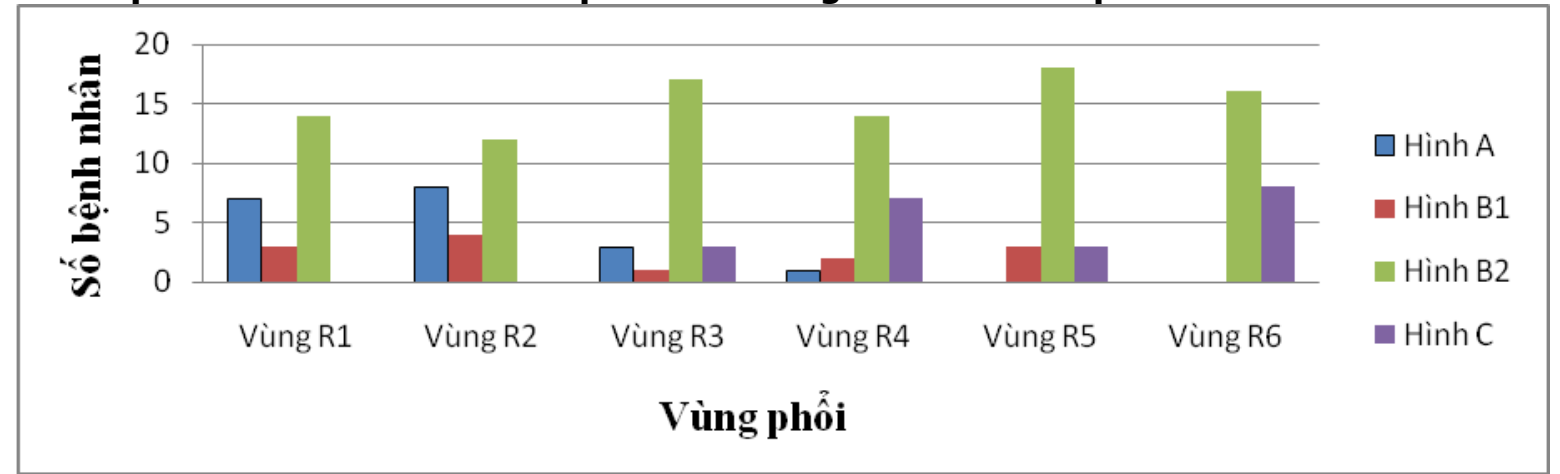

Biểu đồ 2.1. Phân bố hình ảnh siêu âm phổi theo các vùng của phổi phải (trên) và phổi trái (dưới)

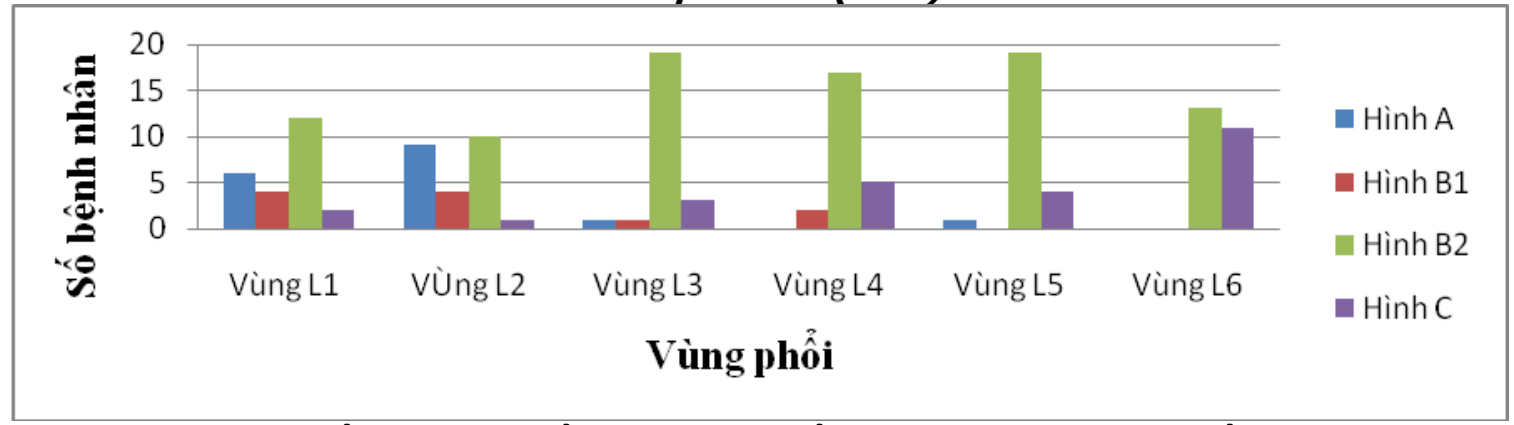

Biểu đồ 2.2. Điểm siêu âm phổi theo các vùng của phổi

Nhận xét: Hình $A$ chủ yếu xuất hiện ở vùng $R 1, R 2, L 1, L 2$, ít hơn ở vùng $L 3$, R3 và không xuất hiện tại vùng R6, L6. Hình đông đặc xuất hiện chủ yếu tại vùng phổi bên và sau đặc biệt nhiều tại vùng $R 4$, R6, L4, L6
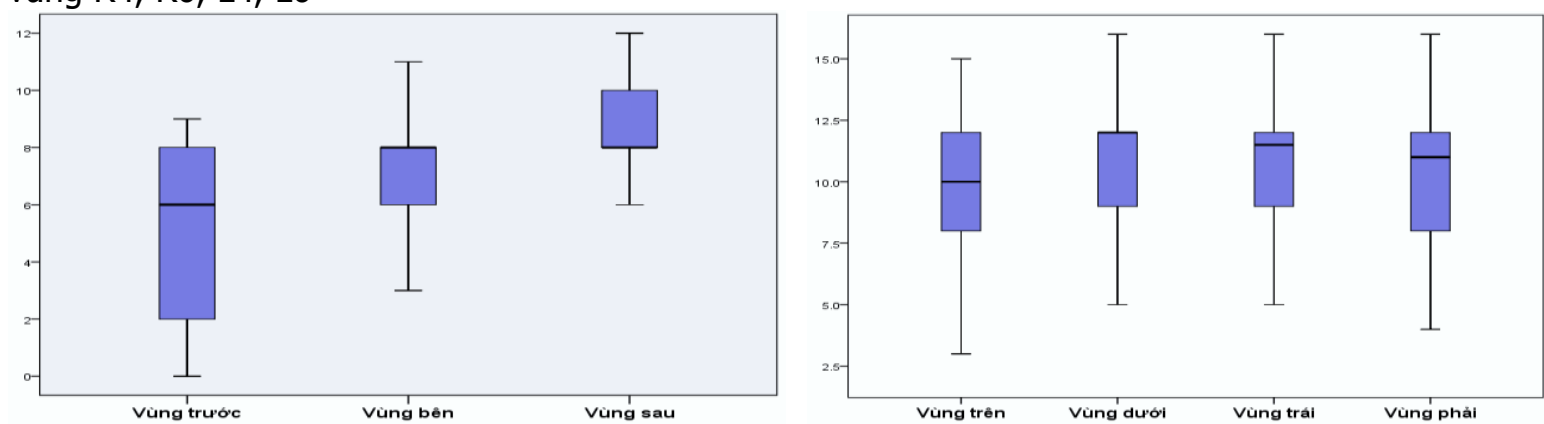

Nhận xét: Điểm siêu âm phổi tăng dần theo vị trí vùng phổi theo chiều từ trước ra sau, từ trên xuống dưới. Điểm siêu âm phổi của vùng phổi phải và trái cũng khác nhau. Sự khác biệt có ý nghĩa thống kê với $p<0,05$. 
Bảng 2.1. Phân bố hình ảnh siêu âm phổi theo mức độ nặng (Berlin 2012)

\begin{tabular}{|c|c|c|c|c|}
\hline \multirow{2}{*}{ Phân nhóm } & \multicolumn{4}{|c|}{ Hình ảnh siêu âm phối n (\%) } \\
\cline { 2 - 5 } & $\mathrm{A}$ & $\mathrm{B} 1$ & $\mathrm{~B} 2$ & $\mathrm{C}$ \\
\hline Nhẹ $(\mathrm{n}=8)$ & $4(50)$ & $3(37,5)$ & $8(100)$ & $3(37,5)$ \\
\hline Vừa $(\mathrm{n}=12)$ & $8(66,7)$ & $10(83,3)$ & $12(100)$ & $9(75)$ \\
\hline Nặng $(\mathrm{n}=4)$ & $2(50)$ & $0(0)$ & $4(100)$ & $3(75)$ \\
\hline
\end{tabular}

Nhận xét: Hình ảnh B2 xuất hiện trên tất cả bệnh nhân nghiên cứu, hình ảnh đông đặc xuất hiện ít ở bệnh nhân ARDS nhẹ, nhiều hơn ở nhóm ARDS nặng và trung bình. Nhóm ARDS nặng không thấy xuất hiện hình ảnh B1
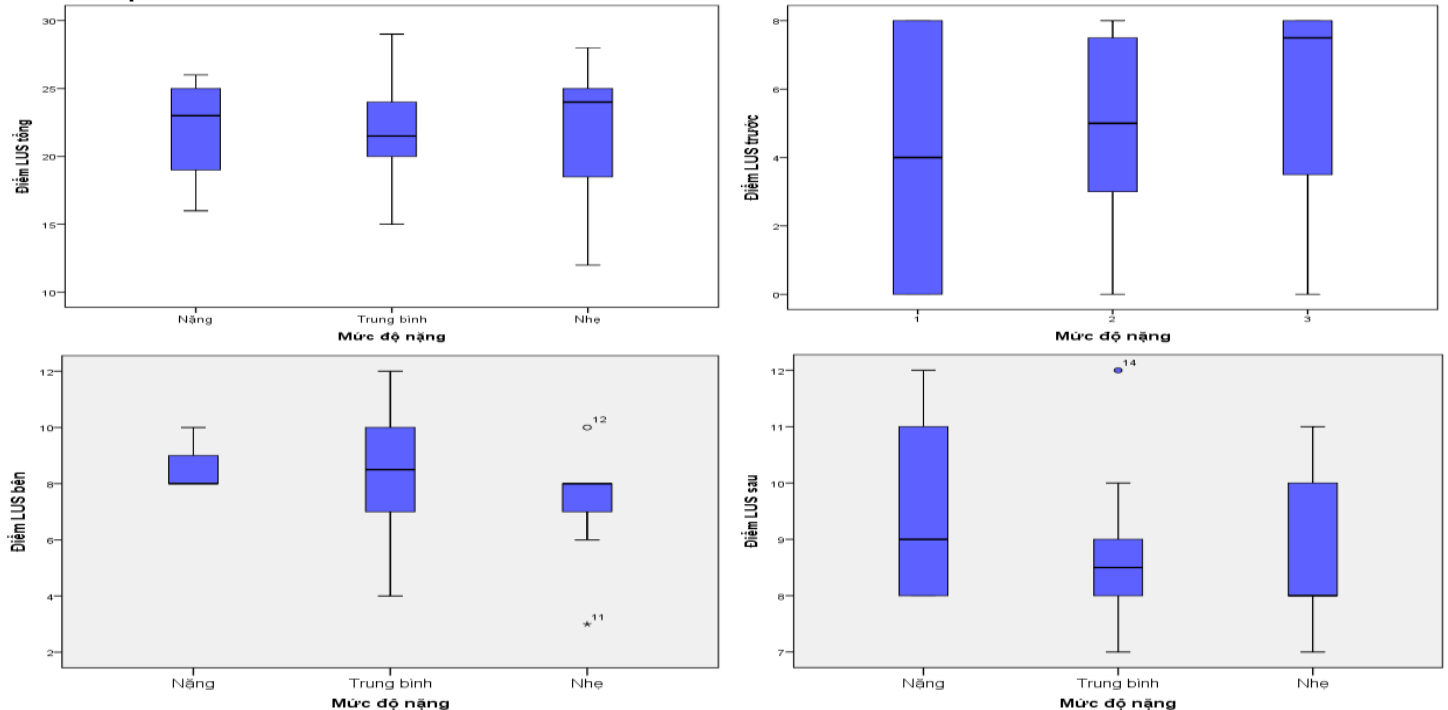

Biểu đồ 2.3. Điểm siêu âm phổi vừng trước, bên, sau

và tổng theo mức độ năng của ARDS (Berlin 2012)

Nhận xét: Điểm siêu âm phổi vùng và siêu âm phổi tổng không liên quan với mức độ nặng của ARDS theo phân loại Berlin. Sự khác biệt không có ý nghĩa thống kê với $p<0,05$.

\section{BÀN LUÂN}

1. Đặc điểm chung của nhóm nghiên cứu. Nghiên cứu được thực hiện trên 24 bệnh nhân ARDS được thông khí xâm nhập có độ tuổi trung bình là $44 \pm 13$ (năm), nam giới chiếm đa số với tỷ lệ nam/nữ: 2/1 (Bảng 1.1). Trong các yếu tố nguy cơ dẫn đến ARDS, căn nguyên chủ yếu vẫn là viêm phổi $(79 \%)$. Trong ngày thú nhất, chỉ số LIS, SOFA cao còn $\mathrm{PaO} 2 / \mathrm{FiO} 2$ và độ giãn nở phổi giảm nhiêu (Bảng 1.3). Hầu hết các phương pháp điều trị đều đã được áp dụng trên nhóm bệnh nhân nghiên cứu từ điều trị nền tảng (an thần, giãn cơ , thở máy theo ARDSnet, kháng sinh) cho đến điều trị cứu vãn (mở phổi, nằm sấp, ECMO), tuy nhiên tỷ lệ tử vong vẫn cao (67\%) (Bảng 1.2)

2. Đăc điểm hình ảnh siêu âm phổi theo bảng điểm siêu âm phổi

2.1. Phân bố hình ảnh theo mức độ nặng. Hình ảnh B2 xuất hiện trên tất cả bệnh nhân trong nghiên cứu (Bảng 2.1), khác với nghiên cứu của Sanjan khi hình ảnh B2 chỉ xuất hiện ở $25 \%$, $70 \%$ và $92 \%$ trên nhóm bênh nhân nhẹ, vừa và nặng ${ }^{5}$. Hình ảnh $\mathrm{B} 2$ thể hiện sự giảm thông khí phổi mức độ nặng, khi có nước, dịch rỉ viêm, fibrin xâm nhập vào mô kẽ phổi. Có sự khác biệt như vậy có thể do thời gian từ khi chẩn đoán $A R D S$ đến thời điểm lấy vào nghiên cứu của hai nghiên cứu khác nhau. Đa số bệnh nhân trong nghiên cứu của chúng tôi $(71 \%)$ có thời gian từ khi chẩn đoán ARDS đến khi lây vào nghiên cứu trên 48 giờ, trong khi đó nghiên cứu của Sanjan thực hiện trên bệnh nhân ARDS tại khoa Cấp cứu nên đa số trong giai đoạn sớm.

\subsection{Phân bố hình ảnh theo vừng của} phổi. Kiểu hình phân bố trên siêu âm phổi trong nghiên cứu của chúng tôi giống nghiên cứu của Sanjan, hình ảnh phân bố không đều với hình ảnh $B 2, C$ tâp trung chủ yếu tại vùng phổi phụ thuộc trọng lực vùng sau và dưới, hình ảnh $A$ tập trung ở vùng phổi trước không phụ thuộc trọng lực (Biểu đồ 2.1). Kiểu hình này tương tự như phân bố của tổn thương phổi ARDS khảo sát trên phim cắt lớp vi tính. Điểm siêu âm phổi tăng 
dần theo thứ tự trước, bên, sau, từ trên xuống dưới sự khác biệt có ý nghĩa thống kê với $p$ < 0,05 (Biểu đồ 2.2). Hơn nữa điểm siêu âm phổi vùng sau đóng góp nhiều nhất trong tổng điểm siêu âm của cả phổi giống với nghiên cứu của Luigi Pisani $(2019)^{6}$. Điều này được có thể giải thích do ngoài tác dụng của trọng lực, vùng phổi này còn chịu tác động của lực bên ngoài như áp lực ổ bụng, dịch màng phổi, áp lực ổ bụng và kích thước tim.

Điểm siêu âm phổi tổng và ba vùng trước, bên, sau ở ba phân nhóm mức độ nhẹ, vừa, nặng theo phân loại Berlin khác biệt không có ý nghĩa thống kê với $p>0,05$ (Biểu đồ 2.3) khác với nghiên cứu của Luigi Pisani (2019) khi điểm siêu âm phổi vùng sau tăng dần theo mức độ nă̆ng của ARDS.

3. Hạn chế của nghiên cứu. Nghiên cứu của chúng tôi còn một số hạn chế nhất định. Kết quả siêu âm phổi có được phụ thuộc chủ quan của người nghiên cứu, chúng tôi cũng chưa đưa đánh giá được độ lặp lại (Repeatablity/Testretest reliability), sự nhất quán của người chẩn đoán cũng như giữa những người chẩn đoán (intraobserver và interobserver ). Cõ̃ mẫu của chúng tôi nhỏ, cần có những nghiên bổ sung để đưa đưa ra những kết luận có thể đại diện tốt cho quần thể nghiên cứu.

\section{KẾT LUẬN}

Hình ảnh siêu âm phân bố không đều giữa các vùng phổi với hình ảnh đông đặc, B2 tập trung chủ yễu tại vùng sau, dưới của phổi

\section{TÀI LIỆ THAM KHẢO}

1. Gattinoni $L$, Pesenti A. The concept of "baby lung." Intensive Care Med. 2005;31(6):776-84.

2. Mongodi S, Pozzi M, Orlando A et al. Lung ultrasound for daily monitoring of ARDS patients on extracorporeal membrane oxygenation: preliminary experience. ntensive Care Med. 2018;44(1):123-124.

3. Bouhemad $B$, Brisson $H$, Le-Guen $M$ et al. Bedside ultrasound assessment of positive endexpiratory pressure-induced lung recruitment. Am J Respir Crit Care Med. 2011;183(3):341-7.

4. Ferguson N. D, Fan E, Camporota L. The Berlin definition of ARDS: an expanded rationale, justification, and supplementary material. Intensive Care Med. 2012;38(10):1573-82.

5. A. Sanjan, S. Vimal Krishnan, Siju V. Abraham, Babu Urumese Palatty. Utility of Point-of-Care Lung Ultrasound for Initial Assessment of Acute Respiratory Distress Syndrome Patients in the Emergency Department. J Emerg Trauma Shock. 2019;12(4):248-253.

6. Luigi P et al. The diagnostic accuracy for ARDS of global versus regional lung ultrasound scores - a post hoc analysis of an observational study in invasively ventilated ICU patient. Intensive Care Medicine Experimental. 2019;7(Suppl 1):44.

\section{ĐĂC ĐIỂM TRÂM CẢM TRÊN THANG ĐIỂM PHQ-9 Ở BỆNH NHÂN UNG THƯ ĐƯờNG TIÊU HÓA TẠI BỆNH VIỆN K}

\section{TÓM TẮT}

Mục tiêu: Đánh giá đăc điểm trâm cảm trên thang điểm PHQ-9 ở bệnh nhân ung thư đường tiêu hóa tại bệnh viện K. Đối tượng: 124 bệnh nhân đã chẩn đoán xác định ung thư đường tiêu hóa và điều trị tại bệnh viện $K$ từ tháng $8 / 2020$ đến tháng 10/2020. Phướng pháp: Nghiên cứu mô tả cắt ngang. Kết quả: Tỷ lệ nam/nữ là 2,6/1, tuổi trung bình là $57,9 \pm 9,65$. Đa số có trình độ dưới lớp 10 $(57,3 \%)$ và độc thân/góa $(93,5 \%)$. Trầm cảm thường gặp nhất ở ung thư đại trực tràng $(52,4 \%)$, tiếp theo là ung thư thực quản $(27,4 \%)$ và ít nhất ở ung thư da dày $(20,2 \%)$, đa số bệnh nhân ở giai đoạn III-IV $(64,5 \%)$. Có mối liên quan có ý nghĩa thống kê giữa

${ }^{1}$ Bệnh viện $K$

Chịu trách nhiệm chính: Đỗ Tuyết Mai

Email: bsdotuyetmai@gmail.com

Ngày nhận bài: 5.3.2021

Ngày phản biên khoa học: 28.4.2021

Ngày duyệt bài: 6.5.2021

\section{Đỗ Tuyết Mai ${ }^{1}$, Nguyễn Tiến Quang ${ }^{1}$}

trâm cảm với ung thư thực quản ( $\mathrm{p}<0,001$; $\mathrm{OR}=$ $1,009,95 \% \mathrm{CI}=0,359-2,838)$ và ung thu đại trực tràng $(p<0,05 ; O R=0,901,95 \% C I=0,358-2,273)$. Có mối liên quan có ý nghĩa thống kê giữa trâm cảm với giai đoan IV với $\mathrm{p}<0,05(\mathrm{OR}=0,196 ; 95 \% \mathrm{CI}=$ 0,058-0,660). Theo thang điểm PHQ-9 có 45,2\% bệnh nhân ung thư đường tiêu hóa có biểu hiên trâm cảm và $17,8 \%$ có trầm cảm mức độ trung bình trở lên cân được can thiệp. Kết luận: Trầm cảm thường gặp ở người bệnh ung thư đường tiêu hoa. Có mối liên quan có ý nghĩa thống kê giữa trầm cảm với ung thư thực quản, đại trực tràng và giai đoạn muộn.

Tư khóa: Trâm cảm, ung thư đường tiêu hóa, đặc điểm, PHQ-9.

\section{SUMMARY}

THE CHARACTERISTICS OF DEPRESSION WITH THE PHQ-9 IN GASTROINTESTINAL

CANCER PATIENTS AT K HOSPITAL

Objective: To assess the characteristic of depression with $\mathrm{PHQ}-9$ in patients with gastrointestinal cancers at K hospital. Subject: 124 patients were 